\title{
ESTÁDIOS DE MATURAÇÃO DE CULTIVARES DE Coffea arabica L. EM MONTE CARMELO-MG E SUAS CARACTERÍSTICAS SENSORIAIS
}

\author{
Patrícia Diniz Graciano', Gleice Aparecida Assis', Ana Carolina Silva Siquieroli', Luiz Donizetti Ferreira \\ Junior ${ }^{2}$, Marco lony Santos Fernandes ${ }^{1}$, Carolina Ramos Paiva ${ }^{1}$
}

\author{
Universidade Federal de Uberlândia - UFU - Campus Monte Carmelo, Monte Carmelo/MG, patriciagraciano01@hotmail.com, carol@ \\ ufu.br, gleiceufu@gmail.com, marcoionys@gmail.com, carolinaramospaiva255@gmail.com \\ Cooperativa Regional de Cafeicultores em Guaxupé. Monte Carmelo/MG, luizdfj@ @hotmail.com
}

Autor para correspondência: Patrícia Diniz Graciano, patriciagraciano01@hotmail.com

\begin{abstract}
RESUMO: Objetivou-se com este trabalho avaliar os estádios de maturação dos frutos de cultivares de café arábica cultivadas em Monte Carmelo-MG e a influência na qualidade sensorial. 0 experimento foi implantado na Fazenda Vitória no município de Monte Carmelo, em outubro de 2011. 0 delineamento experimental utilizado foi o de blocos casualizados com três repetições, sendo que cada parcela foi composta por cinco plantas. As cultivares estudadas foram Acauã, Catucaí 2 SL, Catucaí Amarelo 3 SM, Catucaí Vermelho 19/8, Sarchimor MG 8840 e Paraíso MG H 419-1. Em julho de 2015 foi realizada a colheita por derriça manual para a avaliação dos estádios de maturação dos frutos e posteriormente feita análise sensorial na COOXUPÉ - Núcleo de Monte Carmelo (Cooperativa Regional dos Cafeicultores em Guaxupé Ltda.). Os dados foram submetidos à análise de variância, com aplicação do teste F. Para as comparações entre as médias, foi realizado o teste de Tukey a 5\% de probabilidade. Os resultados demonstraram que os estádios de maturação influenciaram na qualidade da bebida de todas as cultivares estudadas. A cultivar Paraíso MG H 419-1 foi classificada com o tipo de bebida dura verde com as maiores porcentagens de frutos verdes dentre todas as cultivares. Desta forma, conclui-se que os estádios de maturação dos grãos de café interferem na qualidade da bebida, mas não é somente ela que dita a classificação final, e sim todo o processo de colheita, pós-colheita e preparo das amostras para análise sensorial das mesmas. Além disso, condições ambientais durante o ciclo fenológico do café também contribuem para tal classificação, pois o clima, principalmente temperatura e precipitação definem a formação dos frutos.
\end{abstract}

PALAVRAS-CHAVE: Análise sensorial, Coffea arabica, Qualidade de bebida.

\section{CULTIVAR MATURATION STAGES OF Coffea arabica L. IN MONTE CARMELO-MG AND ITS SENSORY CHARACTERISTICS}

ABSTRACT: The objective of this study was to evaluate the maturation stages of the cultivars of arabica coffee cultivars grown in Monte Carmelo-MG and their influence on their sensorial quality. The experiment was implemented at Fazenda Vitória in the municipality of Monte Carmelo in October 2011. The experimental design was a randomized block design with three replications, each plot being composed of five plants. The cultivars studied were Acauã, Catucaí 2 SL, Catucaí Amarelo 3 SM, Catucari Vermelho 19/8, Sarchimor MG 8840 and Paraíso MG H 419-1. In July, 2015, a manual harvesting was carried out to assess fruit maturation stages and later sensorial analysis was carried out at COOXUPÉ - Monte Carmelo Center (Cooperativa Regional dos Caicultadores in Guaxupé Ltda.). The data were submitted to analysis of variance, with application of the test $F$. For the comparisons between the means, the Tukey test was performed at $5 \%$ probability. The results showed that the maturation stages influenced the quality of the beverage of all cultivars studied. The cultivar Paraíso MG H 419-1 and Catucaí Amarelo 3 SM were classified with the type of hard drink green and hard and with the highest percentages of green fruits. Thus, it is concluded that the stages of maturation of coffee beans interfere with the quality of the beverage, but not only the final classification, but also the whole process of harvesting, post-harvesting and preparation of the samples for sensorial analysis of the coffee. In addition, environmental conditions during the coffee phenological cycle also contribute to this classification, since the climate, mainly temperature and precipitation, define the formation of the fruits.

KEYWORDS: Sensory analysis, Coffea arabica L., Drink quality. 


\section{INTRODUÇÃO}

O Brasil ocupa o ranking de maior produtor e exportador mundial de café, além de ser o segundo maior consumidor do produto, o que faz da cafeicultura uma atividade de extrema importância para o país (CARVALHO et al., 2015). A produção de café no Brasil possui grande importância para geração de empregos e renda nas regiões produtoras (CUBRY et al., 2013; RODRÍGUEZ et al., 2013), sendo o café arábica (Coffea arabica L.) o mais produzido no Brasil e no mundo (CONAB, 2016).

A área total plantada no país com a cultura de café (arábica e conilon) totaliza 2,24 milhões de hectares. Desse total, 326,8 mil hectares estão em formação e 1,922 milhão de hectares em produção. A área plantada de café arábica no país totaliza 1,766 milhão de hectares. Minas Gerais detêm a maior área com a espécie, 1,190 milhão de hectares, seguido de São Paulo, com 213 mil hectares (CONAB, 2015).

Há duas principais espécies do gênero Coffea que se destacam comercialmente: C. arabica L., conhecido como café arábica e $C$. canephora Pierre ex A. Froehner, o chamado café robusta, que abrange as variedades Robusta e Conilon (INTERNATIONAL COFFEE ORGANIZATION, 2015).

As espécies possuem diferenças em preço, qualidade e preferência pelos consumidores. Além disso, podem apresentar diferenças tanto na composição química quanto no comportamento de seus componentes durante o processo de torração (SCHOLZ et al., 2011; CONTI et al., 2013; RIBEIRO et al., 2014).

A qualidade do café está ligada diretamente à espécie cultivada. 0 café arábica caracteriza-se por ser mais fino, possuir qualidade superior de bebida, melhor sabor e aroma, baixo teor de cafeína, quando comparado ao robusta, que apresenta menor acidez; é utilizado em blends com o arábica, a fim de obter uma bebida mais encorpada, além de possuir um amargor mais acentuado (LECOLIER et al., 2009).

Há vários outros fatores durante 0 processo de produção que influenciam a qualidade da bebida do café, podendo citar os tratos culturais, processo de colheita e pós-colheita que englobam o processamento, beneficiamento, secagem e armazenamento
(GIOMO e BORÉM, 2011; RIBEIRO, 2014), além de características do genótipo e condições climáticas como altitude, temperatura e umidade (BERTRAND et al., 2012; TAVEIRA et al., 2015). Dessa forma, devem ser tomados cuidados com estes processos para que o café produzido resulte em uma bebida de qualidade superior, superando o exigente paladar dos consumidores (RIBEIRO, 2014).

Os frutos de uma mesma planta podem se apresentar em diferentes estádios de maturação: desde chumbinho, verde, verde cana, cereja, passa e seco. No entanto, a colheita deve ser feita quando a maioria dos frutos estiver no estádio cereja, estando com a maturidade fisiológica completa, e resultando em um café de qualidade superior (CARVALHO e CHALFOUN, 2000), afirmando que o estádio de maturação dos frutos também interfere na qualidade da bebida (MATIELLO et al., 2005).

A avaliação da qualidade do café é realizada com base em análises físicas, que incluem forma, tamanho, uniformidade dos grãos, análise bioquímica e sensorial (SAATH et al., 2012). A análise sensorial consiste em classificar o café quanto à bebida, levando-se em consideração o sabor e o aroma que o café apresenta na "prova de xícara", a qual classifica a bebida dos cafés arábica nos padrões mole, estritamente mole, apenas mole, dura, riada, rio e rio zona, conforme o estabelecido pelas normas oficiais de classificação do café regidas pela Instrução Normativa $n^{0} 8$, de 11 de junho de 2003, do Ministério de Estado da Agricultura, Pecuária e Abastecimento (BRASIL, 2003).

Dessa forma, objetivou-se com este trabalho avaliar os estádios de maturação dos frutos de cultivares de café arábica cultivadas em Monte Carmelo-MG e a influência na qualidade sensorial.

\section{MATERIAL E MÉTODOS}

O experimento foi conduzido na Fazenda Vitória, município de Monte Carmelo. A cidade localiza-se na mesorregião do Triângulo Mineiro e Alto Paranaíba, no estado de Minas Gerais. A área está situada a uma altitude de $890 \mathrm{~m}$, latitude sul de $18^{\circ}$ $44^{\prime} 05^{\prime \prime}$ e longitude oeste de $47^{\circ} 29^{\prime} 47^{\prime \prime}$. A temperatura varia entre a mínima de $15,2^{\circ} \mathrm{C}$ e a máxima de $32,2^{\circ} \mathrm{C}$, com precipitações anuais médias de $1600 \mathrm{~mm}$ (ROCHA et al., 2014). 
O plantio da lavoura foi realizado em outubro de 2011, utilizando-se mudas de $C$. arabica $L$ das cultivares Acauã, Catucaí $2 \mathrm{SL}$, Catucaí Vermelho 19/8, Sarchimor MG 8840, Catucaí Amarelo 3 SM e Paraíso MG H 419-1, espaçamento de 3,8 $\mathrm{m} \times$ 0,7 m, totalizando 3.760 plantas ha-1. A lavoura foi irrigada utilizando sistema com gotejadores autocompensantes, espaçados a 0,7 m e com vazão de 2,3 litros por hora, sendo irrigada diariamente de segunda a sexta-feira, duas horas por dia.

0 delineamento experimental utilizado foi o de blocos casualizados, com três repetições, sendo que cada parcela foi composta por cinco plantas. A colheita do experimento foi realizada em julho de 2015 por meio de derriça manual no pano.

Durante essa etapa foi mensurado o volume (L) de frutos de cada parcela e retirada uma amostra de 10 litros de cada repetição. Para a determinação da uniformidade de maturação, retirou-se uma amostra representativa de 1 litro de cada parcela experimental para separação dos frutos em diferentes estádios de maturação (chumbinho, verde, verdecana, cereja, passa e seco). 0 volume (L) do café colhido de cada parcela na lavoura foi determinado com uso de um balde graduado. Além disso, foi realizada a determinação da massa $(\mathrm{kg})$, com uma balança portátil.

O preparo do café foi realizado na Fazenda que pertence à Monguilod Empresa Agrícola por processamento "via seca", não havendo mistura com cafés provenientes de varrição. Após a colheita, as amostras foram esparramadas no terreiro de lama asfáltica para secagem natural ao sol, tomando-se o cuidado de espalhá-lo rapidamente, atentando-se para a espessura da camada, que foi de aproximadamente $5 \mathrm{~cm}$ e também revolvendo seis vezes por dia para que não ocorressem processos fermentativos para prejudicar a qualidade dos grãos.

Posteriormente à secagem, foi feito 0 beneficiamento do café no Laboratório de Fitotecnia da Universidade Federal de Uberlândia, Campus Monte Carmelo. 0 processo foi feito retirando o exocarpo, endocarpo e impurezas das amostras utilizando 0 descascador de renda (modelo DRC1, CARMOMAQ). Somente os grãos retidos nas peneiras 16 e acima foram utilizados na análise sensorial.

Das amostras beneficiadas retirou-se uma sub amostra de cada contendo 300 gramas de café beneficiado que foram levadas para o Laboratório de Classificação e Análise de bebida da COOXUPÉ - Núcleo de Monte Carmelo (Cooperativa Regional dos Cafeicultores em Guaxupé Ltda.) onde foram feitas as análises sensoriais às cegas.

0 ponto de torra das amostras para a análise sensorial seguiu os protocolos da cooperativa, sendo equivalentes aos realizados em amostras comercializadas, com a torra mais clara que propicia o aparecimento nítido do sabor e aroma do café para melhor classificação da bebida, e posteriormente realizou-se a moagem.

Em uma xícara pequena, as amostras foram preparadas com infusão de 10 gramas de pó em $100 \mathrm{~mL}$ de água mineral quente ao ponto da primeira fervura. A fragrância foi sentida com café seco. Após misturar com uma pequena concha, o provador avaliou o aroma da infusão. Depois disso, a espuma foi retirada e o café deixado a decantar. A degustação foi iniciada quando o pó estava depositado no fundo da vasilha e a mistura apresentava temperatura de $60^{\circ} \mathrm{C}$.

Com o auxílio da concha, o degustador tomou uma quantidade de líquido, que manteve na boca 0 tempo suficiente para sentir o sabor e memorizar todos os seus detalhes (RIBEIRO, 2010).

A classificação da análise sensorial foi realizada de acordo com a Instrução Normativa $n^{0}$ 8, de 11 de junho de 2003, do Ministério de Estado da Agricultura, Pecuária e Abastecimento (BRASIL, 2003).

Os dados foram submetidos à análise de variância pelo programa SISVAR (FERREIRA, 2008) após 0 atendimento das pressuposições de normalidade dos resíduos, homogeneidade de variâncias e aditividade de blocos. As médias foram comparadas pelo Teste de Tukey ao nível de $5 \%$ de probabilidade.

\section{RESULTADOS E DISCUSSÃO}

As porcentagens de frutos referentes aos estádios de maturação das cultivares Acauã, Catucaí Amarelo 2 SL, Catucaí Amarelo 3 SM, Catucaí Vermelho 19/8, Sarchimor MG 8840 e Paraíso MG H 419-1, na região de Monte Carmelo-MG, estão apresentadas na Tabela 1. 
Tabela 1. Estádios de maturação de frutos em porcentagem (\%) de cultivares de café arábica na região de Monte Carmelo-MG, 2015.

\begin{tabular}{ccccccc}
\hline Cultivares & Chumbinho & Verde & Verde cana & Cereja & Passa & Coco \\
\hline Paraíso MG H 419-1 & $0,00 \mathrm{~b}$ & $37,92 \mathrm{a}$ & $9,88 \mathrm{~b}$ & $26,32 \mathrm{~b}$ & $13,17 \mathrm{~b}$ & $12,73 \mathrm{~b}$ \\
Catucaí Amarelo 3 SM & $1,06 \mathrm{ab}$ & $18,92 \mathrm{ab}$ & $7,54 \mathrm{~b}$ & $21,11 \mathrm{~b}$ & $27,05 \mathrm{ab}$ & $24,32 \mathrm{~b}$ \\
Catucaí Amarelo 2 SL & $0,00 \mathrm{~b}$ & $16,37 \mathrm{~b}$ & $6,84 \mathrm{~b}$ & $29,79 \mathrm{~b}$ & $35,20 \mathrm{a}$ & $11,81 \mathrm{~b}$ \\
Acauã & $0,63 \mathrm{ab}$ & $7,95 \mathrm{~b}$ & $4,59 \mathrm{~b}$ & $17,13 \mathrm{~b}$ & $24,01 \mathrm{ab}$ & $45,68 \mathrm{a}$ \\
Catucaí Vermelho 19/8 & $1,67 \mathrm{a}$ & $6,43 \mathrm{~b}$ & $4,83 \mathrm{~b}$ & $25,33 \mathrm{~b}$ & $40,54 \mathrm{a}$ & $21,18 \mathrm{~b}$ \\
Sarchimor MG 8840 & $1,74 \mathrm{a}$ & $11,46 \mathrm{~b}$ & $5,74 \mathrm{~b}$ & $25,75 \mathrm{~b}$ & $33,84 \mathrm{ab}$ & $21,47 \mathrm{~b}$ \\
\hline CV (\%) & 67,65 & 41,14 & 59,15 & 23,07 & 25,29 & 22,58 \\
\hline
\end{tabular}

Médias seguidas pela mesma letra na coluna não diferem entre si a $5 \%$ de probabilidade pelo teste de Tukey.

As cultivares Sarchimor MG 8840, Catucaí Vermelho 19/8, Catucaí Amarelo 3 SM e Acauã diferiram significativamente das demais cultivares, conforme 0 teste realizado, apresentando $1,74 \%$, $1,67 \% 1,06 \%$ e $0,63 \%$ de frutos no estádio chumbinho, respectivamente (Tabela 1).

A cultivar Paraíso MG H 419-1 obteve classificação de bebida dura verde (Tabela 2), tendo $37,92 \%$ de frutos verdes, sendo esta a maior porcentagem de frutos neste estádio quando comparada às demais cultivares (Tabela 1). Pode-se atribuir tal classificação de bebida a este elevado percentual de frutos verdes, que confere adstringência à bebida, e ainda ao menor percentual de frutos passa dentre todas analisadas, com 13,17\% (Tabela 1), depreciando a qualidade final da bebida.

Tabela 2. Classificação de bebida de cultivares de café arábica dada pela análise sensorial, Monte Carmelo-MG, 2015.

\begin{tabular}{cc}
\hline Cultivares & Classificação da Bebida \\
\hline Paraíso MG H 419-1 & Dura verde \\
Sarchimor MG 8840 & Dura \\
Catucaí Amarelo 3 SM & Dura \\
Catucaí Vermelho 19/8 & Apenas Mole \\
Acauã & Apenas Mole \\
Catucaí Amarelo 2 SL & Apenas Mole \\
\hline
\end{tabular}

Carvalho e Chalfoun (1985) afirmam que o café colhido no estádio de maturação verde apresenta aspecto e torração de pior qualidade em relação aos frutos cerejas, influenciando na qualidade da bebida. Em experimento realizado por estes autores, a adição de $2 \%$ de frutos verdes em uma amostra de café resultou na depreciação da bebida do tipo "mole" para "apenas mole". Já com 10\%, a amostra regrediu de bebida "mole" para bebida "dura", definida pelo sabor adstringente.

A colheita com grande quantidade de grãos verdes proporciona, além das perdas qualitativas observadas neste trabalho, como alterações no tipo, bebida, sabor e aroma, prejuízos quantitativos, pois será necessária maior quantidade de litros de café colhido na planta para se completar uma saca de café de $60 \mathrm{~kg}$ beneficiada (MESQUITA et al., 2016).

Jáas cultivares CatucaíAmarelo 3SM e Sarchimor MG 8840 classificadas com tipo de bebida dura (Tabela 2) apresentaram maior número de frutos passa, $27,05 \%$ e $33,84 \%$ (Tabela 1), respectivamente, em relação à
Paraíso MG H 419-1, o que pode ser explicado pelo ciclo precoce das mesmas. Estas cultivares apresentaram $18,92 \%$ e $11,46 \%$ de frutos verdes (Tabela 1), sendo estes valores menores do que os encontrados para a cultivar Paraíso MG H 419-1. Dessa forma, os distintos valores de frutos passa e verde quando equiparados aos da cultivar Paraíso MG H 419-1 demonstram contribuição para a classificação da bebida.

Porém, quando se compara a porcentagem de frutos passa das cultivares Acauã, Catucaí Amarelo 2 SLe Catucaí 3 SM, evidencia-se menores valores, o que pode ter influenciado positivamente para melhor qualidade de bebida destas cultivares como apenas mole.

Frutos que estão no estádio passa podem estar relacionados à fase de senescência, ficando propícios à ação de microrganismos responsáveis pelas fermentações, com produção de álcoois e ácidos que podem acarretar perdas na qualidade, caso estas fermentações ocorram de forma incontrolável e prolongada, como resultado da permanência dos 
frutos na planta por ocasião de colheita atrasada em regiões de clima mais úmido, atribuindo aromas e sabores indesejáveis ao café (MESQUITA et al., 2016). A incidência de frutos neste estádio pode ter colaborado para decréscimo da qualidade de bebida que poderia ter sido estritamente mole e não apenas mole como foi classificada.

Logo após a granação dos frutos, a cor verde intenso passa para verde cana, progredindo para a cor vermelha ou amarela, dependendo da cultivar. Há um aumento da síntese de açúcares, com alterações nos ácidos e compostos fenólicos responsáveis pela adstringência do fruto verde (MESQUITA et al., 2016), 0 que pode ser percebido nas cultivares citadas anteriormente, ou seja, a diminuição da presença de fruto verdes diminuiu tal adstringência e proporcionou um nível maior qualidade da bebida do que quando comparada à bebida dura verde.

Sampaio e Azevedo (1989) relataram em seus trabalhos com C. arabica que a partir da adição de $15 \%$ de frutos secos aos frutos cerejas a qualidade da bebida foi afetada, resultando em bebida "dura", concluindo que a secagem dos frutos na planta interfere na qualidade final da bebida, como relatado para as cultivares Sarchimor MG 8840 e Catucaí Amarelo 3 SM.

$\mathrm{O}$ ciclo produtivo da cultura é afetado pelas condições térmicas que influenciam a qualidade do café. Quando o ciclo é curto, confere-se à bebida adstringência e gosto amargo, contudo, quando há um ciclo maior, as propriedades da bebida são boas, pois as transformações bioquímicas são completas.

Constatou-se neste trabalho que as médias das máximas temperaturas registradas referentes aos meses de setembro a junho oscilaram entre $25,6^{\circ} \mathrm{C}$ e $32,1^{\circ} \mathrm{C}$ (Figura 1), o que pode ter relação com a classificação de bebida dura dessas cultivares. Ortolani et al. (2000) analisando as interações do clima, fenologia e qualidade do café arábica, citaram que em algumas regiões de São Paulo, as temperaturas mais elevadas diminuíram os ciclos entre a florada e a maturação dos frutos, principalmente na fase final do ciclo. Essa condição interferiu na translocação de compostos fenólicos do interior do endosperma para as camadas superficiais, evitando uma coincidência entre a migração total desses compostos e o ponto ideal de colheita. Esse fato atribuiu um sabor adstringente e metálico ao café, conferindo à classificação de bebida "dura".

Figura 1. Dados de temperatura máxima e mínima e de precipitação pluviométrica (agosto 2014 a setembro 2015) contribuindo como base de informações para inferências na safra 2015 do café em Monte Carmelo-MG, 2015. Fonte: Sismet Cooxupé (2014/2015).

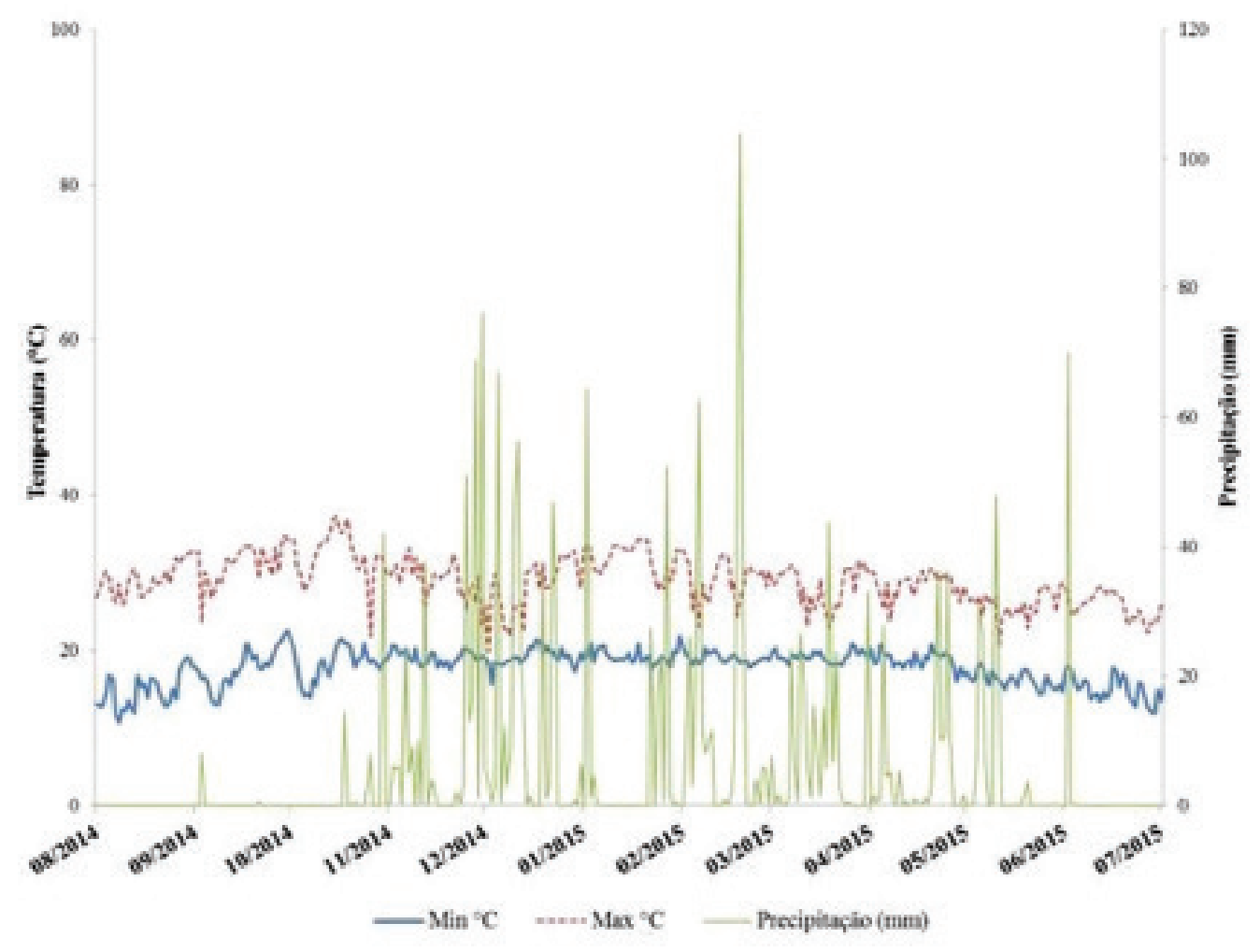


As cultivares Acauã, Catucaí 19/8 e Catucaí 2 SL apresentaram $45,68 \% ; 21,18 \%$ e $11,81 \%$ de frutos no estádio seco, respectivamente. Já para os frutos no estádio passa, relatou-se $24,01 \% ; 40,54 \%$ e $35,20 \%$ na mesma ordem para as cultivares citadas anteriormente (Tabela 1). Observa-se que a cultivar Acauã, embora tenha apresentando maior percentual de frutos secos, apresentou menor percentual de frutos passa em relação às outras duas cultivares com a mesma qualidade de bebida. No entanto, as cultivares Catucaí 19/8 e Catucaí 2 SL apresentaram, respectivamente, os maiores percentuais de frutos passa, e menores de frutos secos em comparação a Acauã.

Os estádios de maturação passa e seco influenciaram diretamente a classificação da bebida, conferindo melhor qualidade de bebida em relação às demais.

Segundo Franco (1956) o fatortérmico influencia na maturação dos frutos. Temperaturas médias acima de $23^{\circ} \mathrm{C}$ aceleram 0 desenvolvimento e a maturação dos frutos, ocasionando perdas de qualidade da bebida. Fato este comprovado na safra acompanhada por este estudo que demonstrou altas porcentagens de frutos passa e coco quando comparadas às porcentagens de frutos chumbinho, verde e verde cana (Tabela 1).

Em Minas Gerais, durante os meses de setembro e outubro de 2014, as chuvas foram irregulares e houve registros de temperaturas acima da média em praticamente todas as regiões. Essa condição atrasou a ocorrência das principais floradas, o que prejudicou o desenvolvimento das lavouras e 0 potencial de produção da safra em 2015, interferindo ainda na qualidade de bebida do café (CONAB, 2015).

No entanto, no período da colheita e secagem do café no terreiro não ocorreu precipitação em volumes consideráveis que prejudicassem a qualidade do café, o que pode ser observado em julho de 2015, em que não foi registrada precipitação pluviométrica.

Porém, no mês de maio de 2015 a média de precipitação atingiu $147 \mathrm{~mm}$ que foram bem distribuídos durante 0 mês, 0 que pode ter favorecido os estádios passa e seco dos frutos, acelerando a maturação. Percebe-se que no período de agosto e setembro de 2014 não foi registrada precipitação (Figura 1). Neste período a planta necessita de um estresse hídrico para que ocorra a uniformização da florada resultando na uniformidade de maturação dos frutos com maior qualidade da bebida (MATIELLO et al., 2010).
Até meados do mês de outubro, não houve nenhum registro de chuvas. Este fato pode ter atrasado a formação de frutos chumbinhos elevando as porcentagens de frutos verdes nas cultivares. Este comportamento está de acordo com os estudos de Camargo e Camargo (2001) que afirma que o déficit hídrico na fase de chumbinho (outubro a dezembro) atrasa o crescimento dos frutos.

Durante os meses de abril e maio de 2015, ocorreram precipitações com volumes significativos (Figura 1) o que pode ter influenciado no aumento dos frutos passa e seco ou ainda a presença de microrganismos prejudiciais à qualidade da bebida nos frutos que estavam em estádios de maturação mais avançados.

A uniformidade de maturação dos frutos influenciou a qualidade da bebida das cultivares Acauã, Catucaí Amarelo 2 SL e Catucaí Vermelho 19/8, mas não se pode desconsiderar os diversos fatores que interferem na qualidade da bebida do café. Neste trabalho, a uniformidade de maturação foi utilizada como parâmetro de estudo e relacionada à qualidade da bebida das cultivares, mas segundo Moreira (2015) devem-se considerar as condições climáticas no momento da colheita e secagem, modo de secagem do café, tipo de colheita, ponto de torra, dentre outros fatores que também afetam a qualidade da bebida.

Pode-se citar que o processo de colheita realizado manualmente com o método de derriça no pano não é seletivo. Assim sendo, todos os estádios de maturação foram colhidos sem separação, e isto pode ter influenciado a inferioridade da bebida de algumas cultivares.

Dentre os fatores que condicionam uma bebida ruim (bebida rio), destaca-se 0 amontoamento em carreadores, permanência por muito tempo na planta ou tempo prolongado no terreiro, contribuindo para a ocorrência de infecções de bactérias e fungos, que interferem no sabor e aroma, resultado em uma bebida de pior qualidade e maiores defeitos como pretos e ardidos. Como no trabalho os processos foram conduzidos da melhor forma possível, não houve classificação de bebida muito inferior, como riada, rio, e rio zona.

Desta forma, conclui-se que os estádios de maturação dos frutos do café influenciam diretamente nos atributos sensoriais da bebida na classificação, podendo conferir aspectos negativos que depreciam 
a bebida, atribuindo dessa forma qualidade inferior caracterizando-a como rio, riada ou rio zona ou até mesmo conferindo aroma e sabor agradável resultando em uma bebida de qualidade superior como estritamente mole. Porém, não é somente ela que dita a classificação final, e sim todo o processo de colheita, pós-colheita e preparo das amostras para análise sensorial. Além disso, condições ambientais durante o ciclo fenológico do café também contribuem para tal classificação, pois o clima, principalmente temperatura e precipitação definem a formação e maturação dos frutos.

\section{REFERÊNCIAS BIBLIOGRÁFICAS}

Bertrand, B.; Boulanger, R.; Dussert, S.; Ribeyre, F.; Berthiot, L.; Descroix, F.; Joët, T. Climatic factors directly impact the volatile organic compound fingerprint in Green Arabica coffee bean as well as coffee beverage quality. Food Chemistry, 2012, 135, 2575.

BRASIL. Ministério da Agricultura, Pecuária e Abastecimento. Instrução Normativa $n^{0}$. 8, de 11 de junho de 2003. Regulamento técnico da identidade e de qualidade para a classificação de café beneficiado grão cru. Diário Oficial da República Federativa do Brasil, Brasília, 13 jun. 2003. Seção 1, p. 22-29. Disponivel em: <http://www.ministerio.gov.br>. Acesso em: 20/05/2017.

Camargo, A.P.; Camargo, M. B. P. Definição e esquematização das fases fenológicas do cafeeiro arábica nas condições tropicais do Brasil. Bragantia, 2001, 60, 1, 65-68.

Carvalho, L. M.; Silva, E. A. M.; Azevedo, A. A.; Mosquim, P. R.; Cecon, P. R. Aspectos morfofisiológicos das cultivares de cafeeiro Catuaí Vermelho e Conilon. Pesquisa Agropecuária Brasileira, 2015, 36, 3, 411-416.

Carvalho, V. D.; Chalfoun, S. M. Colheita e preparo de café. Lavras: UFLA/FAEPE, 2000, 36 p.

Carvalho, V. D.; Chalfoun, S. M. Aspectos qualitativos do café. Informe Agropecuário, 1985, 11, 126, 79-92.

COMPANHIA NACIONAL DE ABASTECIMENTO. Acompanhamento da safra brasileira: Café, safra 2015, quarto levantamento, dezembro, 2015. Disponível em
<http://www.conab.gov.br/OlalaCMS/uploads/arquivos/ 15_12_17_09_02_47boletim_cafe_dezembro_2015_2. pdf>. Acesso em: 03 de out. 2017.

COMPANHIA NACIONAL DE ABASTECIMENTO. Séries Históricas. 2016. Disponível em:<http://www. conab.gov.br>. Acesso em: 26 de set. 2017.

Conti, M. C. M. D. et al. Características físicas e químicas de cafés torrados e moídos exóticos e convencionais. Boletim do CEPPA, 2013, 31, 1, 161-172.

Cubry, P.; Bellis, F.; Pot, D.; Musoli, P.; Leroy, T. Global analysis of Coffea canephora Pierre ex Froehner (Rubiaceae) from the GuineoCongolese region reveals impacts from climatic refuges and migration effects. Genetic Resources Crop Evolution, 2013, 60, 483-501.

Ferreira, D. F. Sisvar: um programa para análises e ensino de estatística. Revista Symposium, 2008, 6, 1, $36-41$.

Franco, C. M. Descoloração em folhas de cafeeiros, causada pelo frio. Bragantia, 1956, 15, 131-135.

Giomo, G. S.; Borém, F. M. Cafés especiais no Brasil: opção pela qualidade. Informe Agropecuário, 2011, 32, 261, 7-16.

ICO - INTERNATIONAL COFFEE ORGANIZATION. Estatísticas do Comércio. Disponível em: <http://www. ico.org/pt/trade_statisticsp.asp>. Acesso em: 21 de nov. 2015.

Lecolier, A.; Besse, P.; Charrier, A.; Tchakaloff, T.; Noirot, M. Unravelling the origin of Coffea arabica 'Bourbon pointu' from La Reunion: a historical and scientific perspective. Euphytica, 2009, 168, 1-10.

Matiello, J. B.; Santinato, R.; Garcia, A. W. R.; Almeida, S. R.; Fernandes, D. R. Cultura de café no Brasil: Manual de recomendações. Varginha: Gráfica Santo Antônio, 2010, 542 p.

Matiello, J. B.; Santinato, R.; Garcia, A. W. R.; Almeida, S. R.; Fernandes, D. R. Cultura de Café no Brasil: novo manual de recomendações. Rio de Janeiro: MAPA/ PROCAFÉ, 2005, 434 p. 
Mesquita, C. M., Rezende, J. E.; Carvalho, J. S.; Fabri Júnior, M. A.; Moraes, N. C.; Dias, P. T.; Carvalho, R. M.; Araújo, W. G. Manual do café: colheita e preparo (Coffea arabica L.). Belo Horizonte: EMATER-MG, 2016. 52 p. il. Disponível em: <http://www.sapc embrapa.br/arquivos/consorcio/publicacoes_tecnicas/ livro_colheita_preparo.pdf. Acesso em: 25 de out. 2017.

Moreira, R. V. Caracterização do processo de secagem do café natural submetido a diferentes métodos de secagem. 2015, 116f. Dissertação (Mestrado em Processamento de Produtos Agrícolas) - Universidade Federal de Lavras, 2015.

Ortolani, A.A.; Cortez, J. G.; Pedro Júnior, M. J.; Camargo, M. B. P.; Thomaziello, R. A.; Alfonsi, R. R.; Sarraipa, L. A. S. Clima e qualidade natural de bebida do café arábica no estado de São Paulo. In: Simpósio de pesquisas dos cafés do Brasil, Anais..., 2000, Poços de Caldas. Brasília: Embrapa Café; Minasplan, 2000, $1,662-664$

Ribeiro, J. Prova de xícara. Revista Adega, 2010. Disponível em: <https://revistaadega.uol.com.br/artigo/ prova-de-xicara_1752.html>. Acesso em: 23 de fev. 2019.

Ribeiro, B. B.; Mendonça, L. M. V. L.; Assis, G. A.; Mendonça, J. M. A.; Malta, M. R.; Montanari. F. F. Avaliação química e sensorial de blends de Coffea canephora Pierre e Coffea arabica L. Coffee Science, 2014, 9, 2, 178-186.

Ribeiro, B. B. Perfil sensorial de cafés de cultivares em relação às faces de exposição das plantas e processamentos pós-colheita. 2014, 81f. Dissertação (Mestrado em Ciência dos Alimentos) - Universidade Federal de Lavras.
Rocha, D. K.; Dias, L. V. S. A.; Graciano, P. D.; Silva, L. R. S.; Santos, L. C.; Mundim, L. M. F.; Rodrigues, L.; Pena, L. K.; Pereira, H. M.; Davi1, R.; Mariano, V.; Rocha, B.; Assis, G. A. Desempenho produtivo de cultivares de café na região do Alto Paranaíba, Minas Gerais. Revista Horizonte Científico, 2014, 8, 1-8.

Rodríguez, D.; Cure, J. R.; Gutierrez, A. P.; Cotes, J. M.; Cantor, F. A coffee agroecosystem model: II., dynamics of coffee berry borer. Ecological Modelling, 2013, 248, 203-214.

Sampaio, J. B. R.; Azevedo, I. A. Influência de grãos secos no pé, em mistura com grãos maduros (cereja), sobre a qualidade do café. Congresso Brasileiro de Pesquisas Cafeeiras, Anais..., Maringá-PR, set. 1989.

Saath, R.; Biaggioni, M. A. M.; Borém, F. M.; Broetto, F.; Fortunato, V. A. Alterações na composição química e sensorial de café (Coffea arabica L.) nos processos pós-colheita. Revista Energia na Agricultura, 2012, 27, 2, 96-112.

Scholz, M. B. S.; Figueiredo, V. R. G.; Silva, J. V. N.; Kitzberger, C. S. G. Características físico-químicas de grãos verdes e torrados de cultivares de café (Coffea arabica L.) do IAPAR. Coffee Science, 2011, 6, 3, 245255.

Sismet Cooxupé. Disponível em:<http://sismet. cooxupe.com.br:9000>. Acesso em: 22 nov. 2016.

Taveira, J. H. S.; Borém, F. M.; Rosa, S. D. V. F. Da; Oliveira, P. D.; Giomo, G. S.; Isquierdo, E. P.; Fortunato, V. A. Post-harvest effects on beverage quality and physiological performance of coffee beans. African Journal of Agricultural Research, 2015, 10, 1457. 